\title{
Calorimetric and spectroscopic investigations of interactions between cucurbituril Q7 and gemcitabine in aqueous solutions
}

\author{
Adam Buczkowski ${ }^{1}$ [D $\cdot$ Artur Stepniak $^{1} \cdot$ Pawel Urbaniak $^{2} \cdot$ Bartlomiej Palecz $^{1}$
}

Received: 29 November 2017 / Accepted: 9 April 2018/Published online: 17 April 2018

(C) The Author(s) 2018

\begin{abstract}
Studies on the interactions between cucurbituril Q7 and gemcitabine (Gem) hydrochloride in water were carried out using isothermal titration calorimetry (ITC) and electrospray ionization-mass spectrometry (ESI-MS). According to ITC and ESI-MS, the formation of this complex occurs in both the solution containing excess gemcitabine and the solution containing excess cucurbituril Q7. ITC results confirm the formation of a thermodynamically stable supramolecular complex with stoichiometry 1:1. The inclusion mechanism of Gem inside the cucurbituril macromolecule is spontaneous $(\Delta G<0)$. This process is exothermic $(\Delta H<0)$ and is characterized by the loss of entropy $(\Delta S<0)$.
\end{abstract}

Keywords Cucurbituril Q7 · CB[7] - Gemcitabine hydrochloride · Isothermal titration calorimetry · Protonation constant of gemcitabine

\section{Introduction}

Thermal analysis enables to study interactions occurring inside supermolecular structures built from macromolecules (hosts) and ions/small molecules (guest ligands) [1-6]. Many research centers have carried out studies on the use of cucurbiturils as transporters of toxic medicines [7], including oncological drugs [8-11]. Cucurbiturils (CB, Q) are a relatively new group of macrocyclic compounds, whose structures contain a repeatedly duplicated motif of glycoluril [12]. Individual glycoluril fragments are combined through methylene groups. The number of glycoluril groups $m$ built into the ring defines the size of macromolecules and is provided in a shortened name of the compound as $\mathrm{CB}[m]$ or $\mathrm{Q} m$. A characteristic feature of this group of compounds is the shape of oblate sphere [13], resembling pumpkin (cucurbitaceae). Inside cucurbituril

Adam Buczkowski

adam.buczkowski@chemia.uni.lodz.pl;

buczkowski_adam@tlen.pl

1 Department of Biophysical Chemistry, Faculty of Chemistry, University of Lodz, Pomorska 165, 90-236 Lodz, Poland

2 Department of Inorganic and Analytical Chemistry, Faculty of Chemistry, University of Lodz, Tamka 12, 91-403 Lodz, Poland macromolecule is a passing-through cavity. The orifice edges, so-called portals, consist of carbonyl oxygen atoms. On account of the polar nitrogen groups present in the cucurbituril macromolecule cavity and polarized carbonyl groups of the portals [14], cucurbiturils can include smaller, positively charged ligands $[15,16]$, forming supramolecular guest-host complex, i.e., ligand molecule-cucurbituril macromolecule. The seven-unit cucurbituril (Q7) can include smaller molecules of nucleic bases, their derivatives-nucleosides [17], making it possible to transfer the compound included through the cell membrane [18].

As a model cationic ligand for our studies, we have selected antitumor drug: gemcitabine hydrochloride (Fig. 1) [19]. Gemcitabine or $2^{\prime}$-deoxy- $2^{\prime}, 2^{\prime}$-difluorocytidine is a cytostatic drug from the group of pyridimine $2^{\prime}$-deoxycytidine antimetabolites. The gemcitabine molecule differs from the molecule of $2^{\prime}$-deoxycytidine in that it contains in position $2^{\prime}$ two atoms of fluorine instead of two hydrogen atoms. Gemcitabine shows its therapeutic effect in the $\mathrm{S}$ phase of cell division when it is built into the DNA thread instead of 2'-deoxycytidine, which makes it impossible to replicate DNA and ultimately causes the tumor cell death. Despite its two fluorine atoms, gemcitabine is a hydrophilic molecule [20]. Protonated gemcitabine is much more soluble in water than in oil and has a low partition coefficient $K_{\text {ow }}=0.05$ [20]. Its cation does not insert also in the 


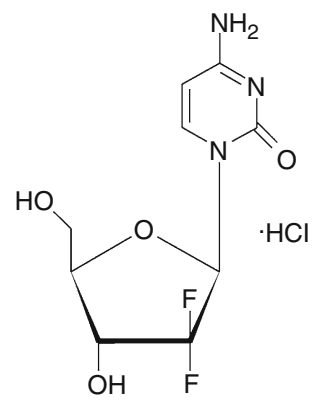

Fig. 1 Semi-structural formula of gemcitabine hydrochloride

hydrophobic core of the phospholipid bilayers (at $\mathrm{pH}=2.4$ ) [20]. Gemcitabine hydrochloride is well water-soluble: $S$ $\geq 33 \mathrm{mM}$ [21], $63.4 \mathrm{mM}$ [22], $83 \mathrm{mM}$ [23], $100 \mathrm{mM}$ [24], and $133 \mathrm{mM}$ [20]. The drug shows an acidic character $p K_{\mathrm{a}}=3.6$ [25], $p K_{\mathrm{a}}=3.58$ [20], and its solubility in aqueous solutions decreases to $51.7 \mathrm{mM}$ with increasing $\mathrm{pH}$ to values between 5 and 9 [20].

Gemcitabine is administered in the form of infusion into a vein in therapy of various cancer types, especially breast cancer, ovarian cancer, non-small-cell lung cancer, pancreatic cancer, and bladder cancer. The gemcitabine therapy is accompanied by numerous side effects including bone marrow suppression, liver and kidney problems, nausea, fever, rash, shortness of breath, and hair loss. The use of nano-carriers well tolerated by organism (e.g., cucurbiturils) can improve the drug stability (during storage) as well as its biocompatibility after administration [26].

Potential applications of the complexes under discussion are determined by the type and energetics of supramolecular interactions [27]. Therefore, the stoichiometry and thermodynamics of the interactions between cucurbituril Q7 and gemcitabine hydrochloride were examined by the dynamic technique of calorimetric titration under conditions of forward system (cucurbituril titrated with the drug) and reverse system (the drug titrated with cucurbituril) in an aqueous medium. The stoichiometry of the cucurbiturilgemcitabine complex in water was studied by means of the electrospray ionization-mass spectroscopy method. Moreover, pH-metric determinations of gemcitabine aqueous solutions were carried out to calculate the drug protonation constant and the distribution curves of protonated and nonprotonated forms of the drug.

The aim of our study was to examine the complex formation process of gemcitabine hydrochloride and cucurbituril Q7 in water, including the determination of the following features: (1) stoichiometry of the cucurbituril Q7-drug complex formed (from ITC and ESI-MS), (2) type of functional groups that could make it possible to combine drug molecules with Q7 (from $\mathrm{pH}$ measurements of Gem solution and literature $p K_{\mathrm{a}}$ value of Q7), and
(3) energetics of interactions between the drug molecules and Q7 macromolecule (from ITC).

\section{Materials and methods}

\section{Materials}

Cucurbit[7]uril hydrate (Sigma-Aldrich, powder containing $80 \%$ Q7 and 20\% water), gemcitabine hydrochloride (Sigma-Aldrich, powder, $\geq 98 \%$ ), hydrochloric acid fixonal (POCh, $1 \mathrm{M}$ ), sodium hydroxide (POCh, $\geq 99.8 \%$ ), sodium chloride (Sigma-Aldrich, $\geq 99.5 \%$ ) were purchased from commercial sources. Water (for ITC and $\mathrm{pH}$ metric titration) was distilled three times and degassed.

\section{pH-metric titration of aqueous gemcitabine hydrochloride solution}

Using a pH-METER N5172 with combined EuroSensor ESAAgP301WM electrode, a $6 \mathrm{mM}$ solution of gemcitabine hydrochloride was titrated with an aqueous $200 \mathrm{mM}$ solution of sodium hydroxide in an aqueous solution of $100 \mathrm{mM}$ sodium chloride (basic electrolyte) at a temperature of $25^{\circ} \mathrm{C}$. The volume of titrated $6 \mathrm{mM}$ solution of gemcitabine hydrochloride was $2 \mathrm{~mL}$ and was prepared by mixing $0.3 \mathrm{~mL}$ of $40 \mathrm{mM}$ gemcitabine hydrochloride solution, $0.2 \mathrm{~mL}$ of $1 \mathrm{M}$ sodium chloride solution, and $1.5 \mathrm{~mL}$ of water. The sample of gemcitabine hydrochloride solution prepared in this way was titrated using $2 \mu \mathrm{L}$ each time of $150 \mu \mathrm{L}$ solution of $200 \mathrm{mM} \mathrm{NaOH}$ in $100 \mathrm{mM}$ $\mathrm{NaCl}$. To determine the protonation constant $p K_{\mathrm{a}}$ of gemcitabine, the titration curve obtained was analyzed in the HyperQuad2008 program [28]. The distribution curves of protonated and non-protonated forms of the drug were calculated using the HySS2009 program [29].

\section{Forward isothermal titration calorimetry of Q7 titrated with gemcitabine hydrochloride in water}

Using the calorimetric titration (VP-ITC MicroCal calorimeter) under isothermal condition $\left(t=25^{\circ} \mathrm{C}\right)$, we measured the thermal effects accompanying the titration of aqueous $0.5 \mathrm{mM}$ solution of cucurbituril Q7 in a $1.4275 \mathrm{~mL}$ cell with an aqueous $5 \mathrm{mM}$ solution of gemcitabine hydrochloride added in 50 rations, $5 \mu \mathrm{L}$ each from an automatic $287.37-\mu \mathrm{L}$ syringe. The time between successive injections amounted to $400 \mathrm{~s}$. Each single injection lasted $10 \mathrm{~s}$. The mixing rate amounted to $416 \mathrm{rpm}$. During titration, the molar ratio of gemcitabine to cucurbituril, [Gem]/[Q7], increased from $0.07 / 1$ to $1.9 / 1$. Three independent titrations of the cucurbituril Q7 solution were carried out with the gemcitabine hydrochloride solution. 
Independently, the thermal effects of diluting cucurbituril Q7 solution (in a cell) were determined, to which water was added by portions (from a syringe) and also those of diluting gemcitabine solution (in a syringe) that was added to water by portions (in a cell). All the measurements were carried out maintaining the same parameter of the calorimeter operation. The thermal effects of direct interactions between cucurbituril macromolecules and gemcitabine hydrochloride were calculated by subtracting from the thermal effect of titrating cucurbituril solution with the drug solution the corresponding effects of diluting the solutions of cucurbituril and drug.

Stoichiometric parameter $n$, equilibrium constant $K$, enthalpy $\Delta H$, and entropy $\Delta S$ of bonding gemcitabine with the macromolecule of cucurbituril Q7, describing the formation process of supramolecular complex, were calculated from the thermal effects $Q$ of the direct interactions between cucurbituril and gemcitabine, using the identicalsite model $(1: n)$ by the method on non-linear multi-parameter regression [30]. The calculations were carried out by means of the Origin MicroCal 7.0 program dedicated to VP-ITC calorimeter.

\section{Reverse isothermal titration calorimetry of gemcitabine hydrochloride titrated with Q7 in water}

In order to perform an additional verification of the stoichiometry of the supramolecular gemcitabine-cucurbituril Q7 complex, calorimetric titration was also carried out (VP-ITC MicroCal calorimeter, $t=25^{\circ} \mathrm{C}$ ) in a reverse system; i.e., the aqueous $120 \mu \mathrm{M}$ solution of gemcitabine hydrochloride was titrated (in a cell) with aqueous $2 \mathrm{mM}$ cucurbituril Q7 solution (in a syringe). Thirty-five portions, $8 \mu \mathrm{l}$ each, of aqueous cucurbituril Q7 were added from a syringe to $1.4275 \mathrm{~mL}$ of gemcitabine hydrochloride solution. The time between successive injections amounted to $1800 \mathrm{~s}$. Each injection lasted $16 \mathrm{~s}$. The mixing rate was $416 \mathrm{rpm}$. During titration, the molar ratio of cucurbituril to gemcitabine, $[\mathrm{Q}] /[\mathrm{Gem}]$, was increasing from $0.2 / 1$ to $3.6 /$ 1. Three independent titrations of gemcitabine hydrochloride with cucurbituril Q7 solution were carried out. Independently, the effects of diluting the cucurbituril solution were determined (in a syringe) that was added by portions to water (in a cell). The thermal effects of diluting the $120 \mu \mathrm{M}$ solution of gemcitabine hydrochloride (in a cell) with water (in a syringe) were negligibly low. The effects of direct interaction between gemcitabine hydrochloride and cucurbituril, corrected by the diluting effects, were analyzed in the program Origin MicroCal 7.0 by the method of non-linear multi-parameter regression, using the identical-site model $(1: n)[30,31]$.

\section{Forward isothermal titration calorimetry of Q7 titrated with gemcitabine hydrochloride in aqueous sodium hydroxide solution and formic buffer solution}

Using the ITC titration under isothermal condition $\left(t=25{ }^{\circ} \mathrm{C}\right)$, we measured (VP-ITC, MicroCal) the thermal effects accompanying the titration of $0.5 \mathrm{mM}$ solution of cucurbituril Q7 (in the cell) with $5 \mathrm{mM}$ solution of gemcitabine hydrochloride added from the syringe in two different solvents: (1) aqueous $20 \mathrm{mM}$ sodium hydroxide solution ( $\mathrm{pH}=12.3$ ) and (2) aqueous $10 \mathrm{mM}$ formic buffer solution $(\mathrm{pH}=3.8)$. Independently, the thermal effects of diluting cucurbituril Q7 solution (in a cell) and gemcitabine solution (in a syringe) were determined. All the measurements were carried out, using the same working parameters of calorimeter as in water. Results were analyzed in Origin MicroCal 7.0, using the identical-site model (1:n) [30, 31].

\section{Reverse isothermal titration calorimetry of gemcitabine hydrochloride titrated with Q7 in formic buffer aqueous solutions}

In order to verify the stoichiometry of the supramolecular gemcitabine-cucurbituril Q7 complex in aqueous $10 \mathrm{mM}$ formic buffer solution ( $\mathrm{pH}=3.8$ ), an additional calorimetric titration (VP-ITC, MicroCal calorimeter, $t=25^{\circ} \mathrm{C}$ ) of $120 \mu \mathrm{M}$ solution of gemcitabine hydrochloride (in a cell) with $2 \mathrm{mM}$ cucurbituril Q7 solution (in a syringe) was also carried out. Independently, the effects of diluting the cucurbituril solution (in a syringe) were determined that was added by portions to formic buffer (in a cell). All the measurements were carried out, using the same working parameters of calorimeter as in water. Results were analyzed in Origin MicroCal 7.0, using the identical-site model (1:n) [30, 31].

\section{Mass spectrometry of Q7-Gem solution}

The bonding of gemcitabine hydrochloride by cucurbituril Q7 in an aqueous solution of sodium acetate was examined by the technique of mass spectrometry with the ionization of the sample tested by electrospray method using a Varian 500-MS LC Ion Trap apparatus in a positive mode. Aqueous mixture with molar ratio of gemcitabine hydrochloride to cucurbituril [Gem]/[Q7] equal about $2 / 1$ was prepared and diluted with aqueous solution of sodium acetate. For measurements by mass spectrometry, sodium acetate was selected as a strong electrolyte (a salt of weak acid and strong base), often used in mass spectrometry as sodium adding agent. The final sample was injected for MS analysis via syringe pump (at a speed of $15 \mu \mathrm{L} \mathrm{min}{ }^{-1}$ ) directly connected to the ESI source. Data were collected 
and analyzed with the dedicated software (Varian MS Workstation), and 16 scans were averaged for each spectrum. The spectrometer was operated at a capillary voltage of $3000 \mathrm{~V}\left(300{ }^{\circ} \mathrm{C}\right)$ and a cone voltage of $30 \mathrm{~V}\left(80^{\circ} \mathrm{C}\right)$. Acquisition of data was adjusted at the standard (for this apparatus) range $m / z, 699.5-1600.5$, and the obtained mass spectrum is presented as raw data with minimal smoothing and without resolution enhancement.

\section{Results}

\section{pH-metric titration of aqueous gemcitabine hydrochloride solution}

To calculate the deprotonation constant of gemcitabine in aqueous solutions and the distribution curves of non-protonated $\left(\mathrm{L}-\mathrm{NH}_{2}\right)$ and protonated form $\left(\mathrm{L}-\mathrm{NH}_{3}^{+}\right)$, the $\mathrm{pH}$ metric titration was carried out in $6 \mathrm{mM}$ gemcitabine hydrochloride solution with aqueous $200 \mathrm{mM}$ sodium base solution in aqueous $100 \mathrm{mM}$ sodium chloride solution as basic electrolyte (Fig. 2). The dissociation constant of the gemcitabine cation, calculated in the HyperQuad2008 program, amounted to $p K_{\mathrm{a}}=3.95$. Small discrepancy between the measured $p K_{\mathrm{a}}$ value of gemcitabine and the literature value 3.58 [20] may arise from different ionic strength. Value of $p K_{\mathrm{a}}=3.95$ was used to calculate the distribution curves of non-protonated form $\left(\mathrm{L}^{\left.-\mathrm{NH}_{2}\right)}\right.$ and protonated form $\left(\mathrm{L}^{-} \mathrm{NH}_{3}^{+}\right)$of gemcitabine using the HySS2009 program (Fig. 3).

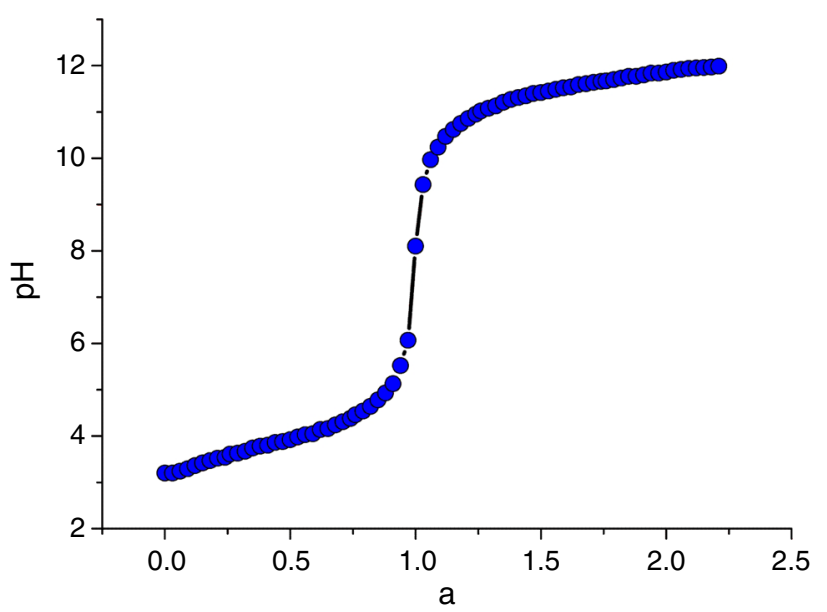

Fig. 2 Curve of pH-metric titration of $6 \mathrm{mM}$ solution of gemcitabine hydrochloride with aqueous $200 \mathrm{mM}$ solution of sodium base in a medium of $100 \mathrm{mM}$ sodium chloride (basic electrolyte) as a function of the titration fraction $a$ of the drug at a temperature of $25^{\circ} \mathrm{C}$

\section{Forward isothermal titration calorimetry of Q7 titrated with gemcitabine in water}

To examine the stoichiometry and thermodynamics of the cucurbituril-gemcitabine complex formation in mixtures with a high drug content, the calorimetric titration was carried out under isothermal conditions $\left(t=25^{\circ} \mathrm{C}\right)$ in a straightforward system; i.e., the cucurbituril macromolecule solution was titrated with the ligand (drug) solution. The thermal effects of titrating the aqueous $0.5 \mathrm{mM}$ cucurbituril Q7 solution $(\mathrm{pH}=4.3)$ with the aqueous $5 \mathrm{mM}$ gemcitabine hydrochloride solution were measured (Figs. 4a, 5a). Once the experiment was completed, the $\mathrm{pH}$ of the titrated solution amounted to 3.8. The thermal effects of the direct interaction between cucurbituril and the drug (Fig. 5b) were determined by subtracting the independently measured thermal effects of diluting gemcitabine (Figs. 4b, 5a) and cucurbituril (Figs. 4c, 5a) from the thermal effects accompanying the titration (Figs. 4a, 5a). Using the identical-site model, the thermal effects of the direct interaction between cucurbituril and gemcitabine were described, calculating (Origin MicroCal 7.0) the stoichiometric parameter $n$, indicating the number of gemcitabine molecules bonded by the cucurbituril macromolecule as well as the constant of complex formation $K$ and the thermodynamic functions of bonding: enthalpy $\Delta H$, entropy $\Delta S$, and free energy $\Delta G$ (Table 1 , line 1).

The results obtained indicate that in aqueous mixtures of cucurbituril and gemcitabine hydrochloride with a high content of the drug, a thermodynamically stable,

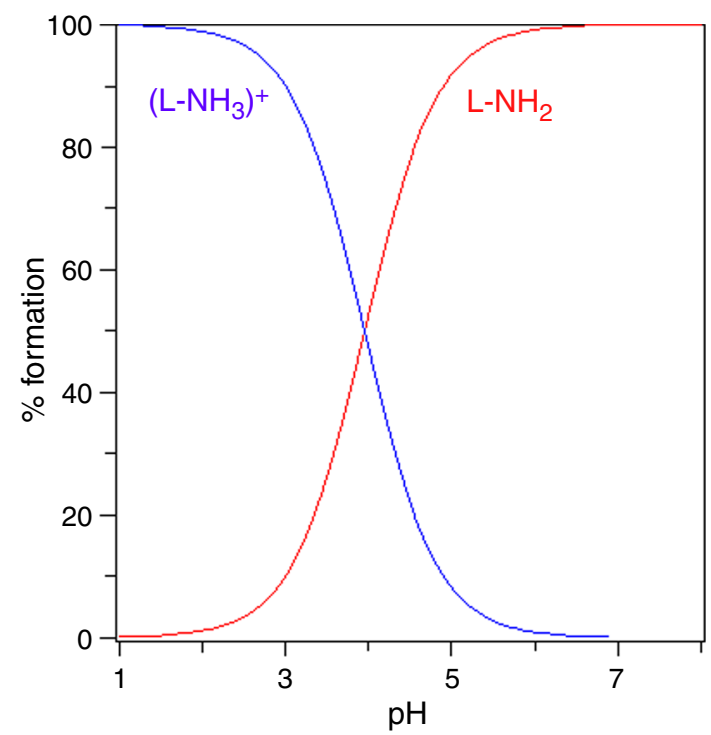

Fig. 3 Percentage formation of protonated $\left(\mathrm{L}-\mathrm{NH}_{3}^{+}\right)$and deprotonated $\left(\mathrm{L}-\mathrm{NH}_{2}\right)$ gemcitabine in aqueous solutions as a function of $\mathrm{pH}$. Distribution curves were calculated in HySS2009 software for $p K_{\mathrm{a}}=3.95$ 

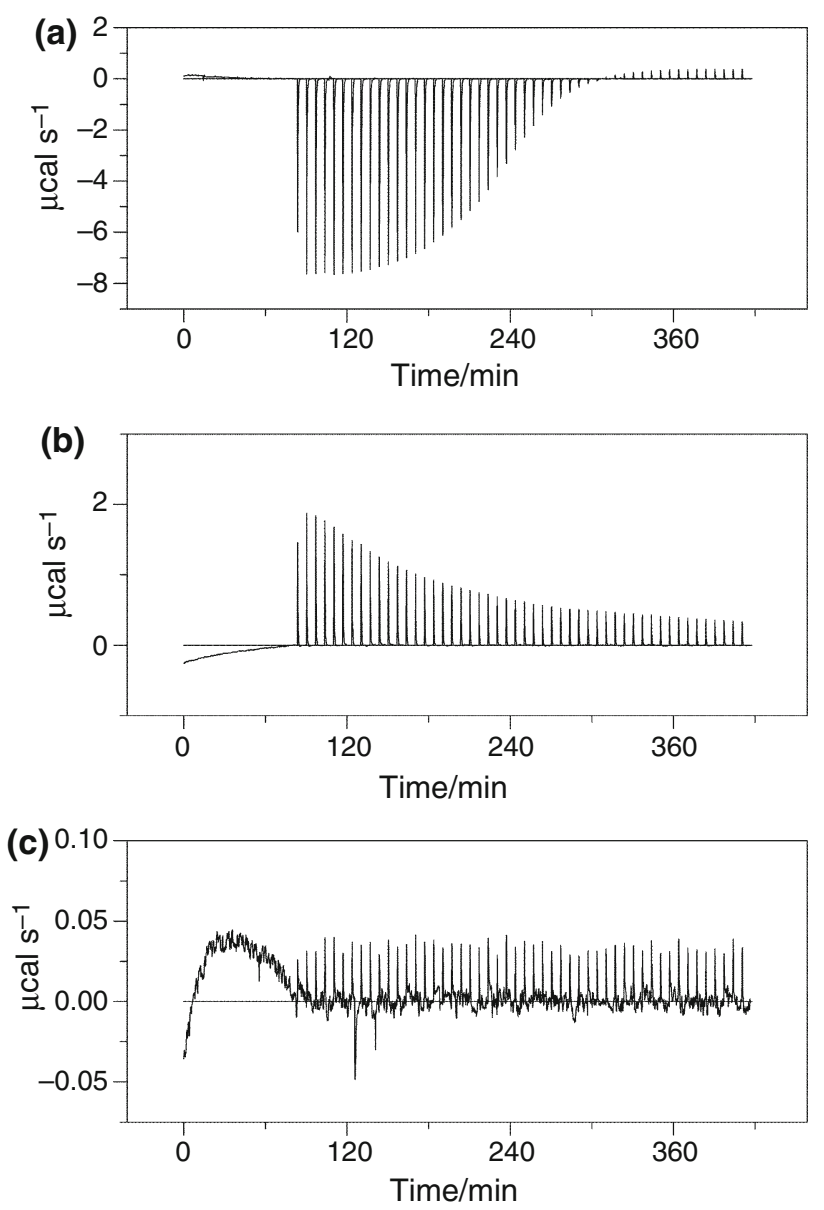

Fig. 4 Curves of thermal power as a function of time for: a titration of aqueous $0.5 \mathrm{mM}$ cucurbituril Q7 solution with aqueous $5 \mathrm{mM}$ gemcitabine hydrochloride solution, b dilution of $5 \mathrm{mM}$ gemcitabine hydrochloride in water, and $\mathbf{c}$ dilution of aqueous $0.5 \mathrm{mM}$ cucurbituril Q7 solution in water supramolecular complex is formed $(\Delta G<0)$. The process of cucurbituril saturation by gemcitabine is exothermic $(\Delta H<0)$ and is accompanied by an increase in the degree of reagent order $(\Delta S<0)$. Close to unity, the value of stoichiometric parameters $n=0.85 \pm 0.05$ shows that the complex with stoichiometry 1:1 predominates in the solution tested. The insignificantly lower than unity value of stoichiometric parameter $n=0.85 \pm 0.05$ may result from the following:

1. the uncertainties in the concentrations of reactants,

2. the hydrolysis of the gemcitabine cation in an aqueous medium to a neutral molecule that is bonded by the negatively polarized cavity and the cucurbituril portals to a lesser extent than the gemcitabine cation. Both presented in the solution gemcitabine species (cationic and neutral) may bind with different affinity, because a difference in a positive or neutral charge may not hinder enough binding phenomenon. If so, the stoichiometry should still be around 1:1, but the affinity would be higher or lower depending on which species predominates and which species shows higher/lower affinity.

3. the lower stoichiometric parameter may also suggest that apart from complex QL, a complex with stoichiometry $\mathrm{Q}_{2} \mathrm{~L}$ occurs in the solution to a lesser extent.

To verify that three possibilities, we performed the ITC titration: (1) in a reverse system in water, (2) in forward system in sodium hydroxide solution, and (3) in forward and reverse systems in formic buffer.
Fig. 5 a Thermal effects of the forward ITC titration of aqueous $0.5 \mathrm{mM}$ cucurbituril Q7 solution with aqueous $5 \mathrm{mM}$ gemcitabine hydrochloride solution (filled black square) and corresponding effects of dilution of gemcitabine hydrochloride (filled black circle) and cucurbituril Q7 (filled black diamond) and b thermal effects of direct interactions between cucurbituril Q7 and gemcitabine hydrochloride (filled black square) described by the identical-site model (solid line)
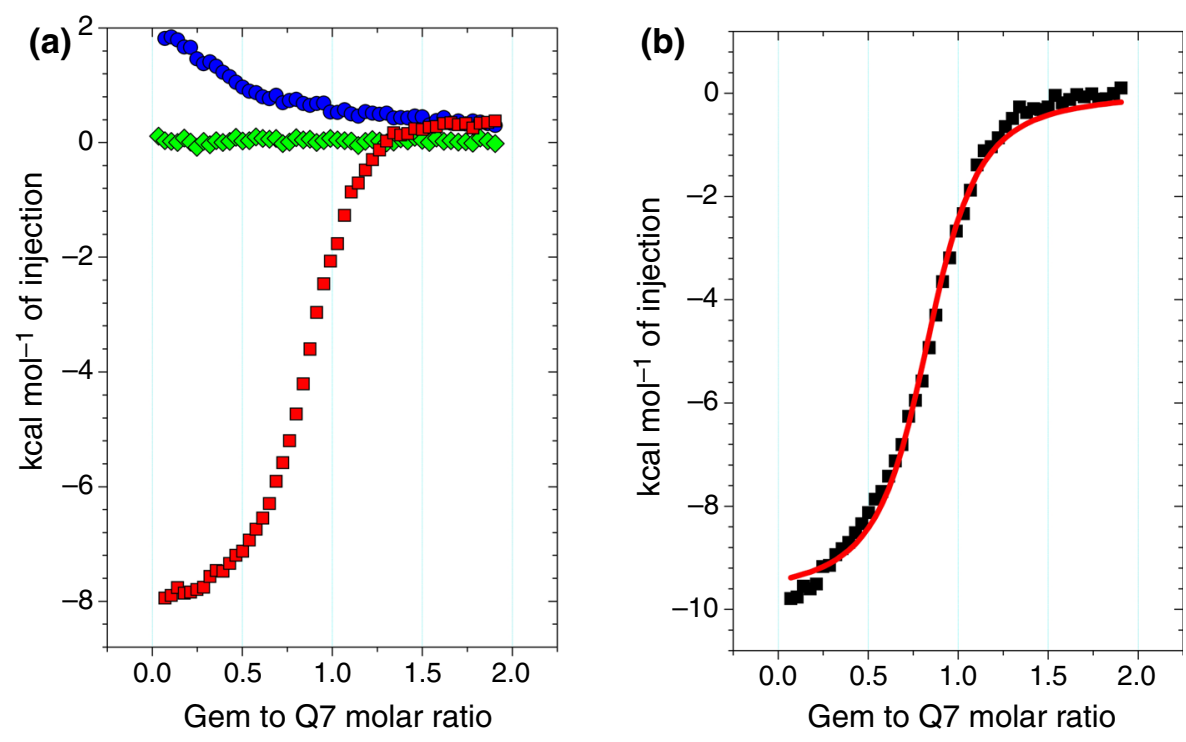
Table 1 Thermodynamic parameters of the supramolecular cucurbituril-gemcitabine complex formation in an aqueous medium at $25{ }^{\circ} \mathrm{C}$ determined by the ITC technique

\begin{tabular}{llllll}
\hline Titration type & $n$ & $K / \mathrm{M}^{-1}$ & $\Delta H / \mathrm{kcal} \mathrm{mol}^{-1}$ & $T \Delta S / \mathrm{kcal} \mathrm{mol}^{-1}$ & $\Delta G / \mathrm{kcal} \mathrm{mol}^{-1}$ \\
\hline Q7 with Gem & $0.85 \pm 0.05$ & $79000 \pm 30000$ & $-9.6 \pm 0.3$ & $-2.9 \pm 0.5$ & $-6.7 \pm 0.2$ \\
Gem with Q7 & $1.05 \pm 0.06$ & $38000 \pm 3000$ & $-8.1 \pm 0.6$ & $-1.8 \pm 0.8$ & $-6.3 \pm 0.2$ \\
\hline
\end{tabular}

\section{Reverse isothermal titration calorimetry of gemcitabine titrated with Q7 in water}

In order to verify the stoichiometry and thermodynamics of cucurbituril-gemcitabine complex formation in mixtures with a high content of cucurbituril, the calorimetric titration was carried out under isothermal conditions $\left(t=25{ }^{\circ} \mathrm{C}\right)$ in a reverse system. The thermal effects of titrating the aqueous $120 \mu \mathrm{M}$ solution of gemcitabine hydrochloride $(\mathrm{pH}=4.1$ ) with the aqueous $2 \mathrm{mM}$ solution of cucurbituril Q7 were measured (Figs. 6a, 7a). After titration, the $\mathrm{pH}$ value of the solution amounted to 3.8. The thermal effects of the direct interaction between the drug and cucurbituril (Fig. 7b) were determined by subtracting from the thermal effects accompanying titration (Figs. 6a, 7a) the independently measured thermal effects of diluting cucurbituril Q7 (Figs. 6b, 7a). The effects of diluting the $120 \mu \mathrm{M}$ solution of gemcitabine hydrochloride (in a cell) with water (in a syringe) were negligibly low. Using the identical-site model, the thermal effects of the direct
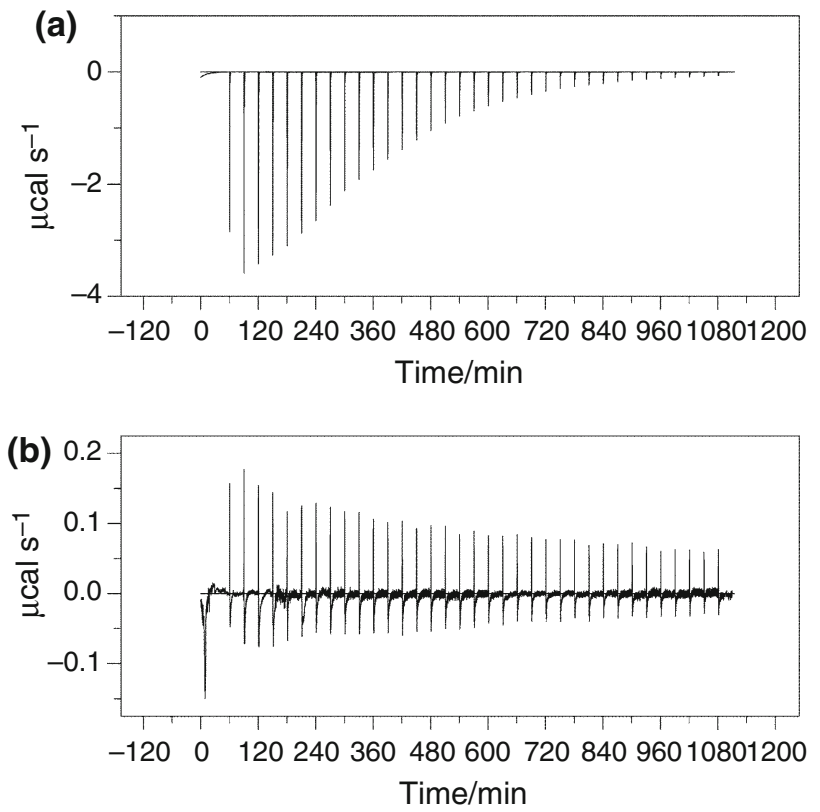

Fig. 6 Curves of thermal power as a function of time for: a titration of aqueous $120 \mu \mathrm{M}$ gemcitabine hydrochloride solution with aqueous $2 \mathrm{mM}$ cucurbituril Q7 solution and $\mathbf{b}$ dilution of $2 \mathrm{mM}$ cucurbituril Q7 solution in water interaction between gemcitabine hydrochloride and cucurbituril were described by calculating (Origin MicroCal 7.0) the stoichiometric parameter $n$, indicating the number of cucurbituril molecules bonded by the molecule of the drug tested, as well as the constant of complex formation $K$ and the thermodynamic functions of bonding: enthalpy $\Delta H$, entropy $\Delta S$, and free energy $\Delta G$ (Table 1 , line 2).

The results obtained indicate that in the aqueous mixtures of cucurbituril and gemcitabine with a high content of the former reagent, a thermodynamically stable supramolecular complex is formed $(\Delta G<0)$. The bonding process of gemcitabine by cucurbituril is exothermic $(\Delta H<0)$ and is accompanied by an increase in the degree of reagent order $(\Delta S<0)$. Calculated according to the identical-site model, the parameters of bonding gemcitabine with cucurbituril (Table 1, line 2) are similar within the limits of measurement uncertainty to the results of the straightforward titration of cucurbituril with gemcitabine (Table 1, line 1). The stoichiometric parameter value obtained $n=1.05 \pm 0.06$ confirms that in the mixture of both components with a high content of cucurbituril, a complex with stoichiometry $1: 1$ is formed in an aqueous medium as in aqueous mixtures of both components with a high content of gemcitabine.

\section{Forward isothermal titration calorimetry of Q7 titrated with gemcitabine in aqueous sodium hydroxide solution and formic buffer solution}

To examine whether non-protonated gemcitabine molecules bind with cucurbituril Q7 macromolecules forming supramolecular complex in basic environment, the $0.5 \mathrm{mM}$ cucurbituril Q7 macromolecule solution was titrated with gemcitabine solution in aqueous $\mathrm{NaOH}$ environment, $\mathrm{pH}=12.3$, under isothermal condition $\left(t=25^{\circ} \mathrm{C}\right)$ (Figs. 8a, 9a). Independently, thermal effects of diluting gemcitabine solution were measured (Figs. 8b, 9a). The effects of diluting the $0.5 \mathrm{mM}$ cucurbituril Q7 solution (in a cell) with sodium hydroxide solution (in a syringe) were negligibly low. Thermal effects of titration cucurbituril Q7 with gemcitabine in strong basic media $(\mathrm{pH}=12.3)$ are low and comprise mainly of the effects of ligand dilution. Low values of thermal effects of direct interactions 
Fig. 7 a Thermal effects of the reverse ITC titration of aqueous $120 \mu \mathrm{M}$ gemcitabine hydrochloride solution with aqueous $2 \mathrm{mM}$ cucurbituril Q7 solution (filled black square) and corresponding effects of dilution of cucurbituril Q7 (filled black circle) and b thermal effects of direct interactions between gemcitabine hydrochloride and cucurbituril Q7 (filled black square) described by the identical-site model (solid line)

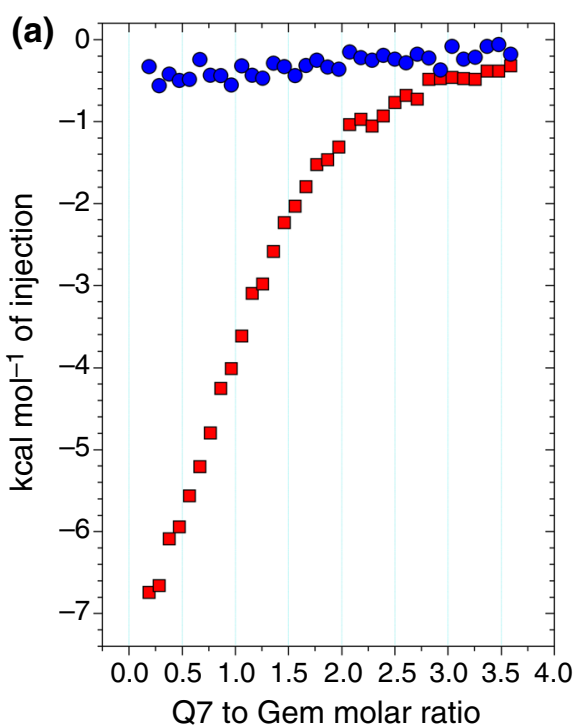

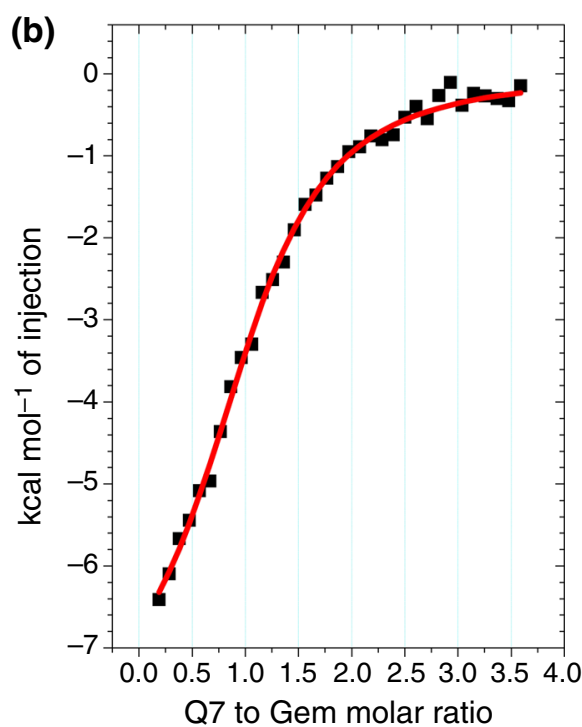
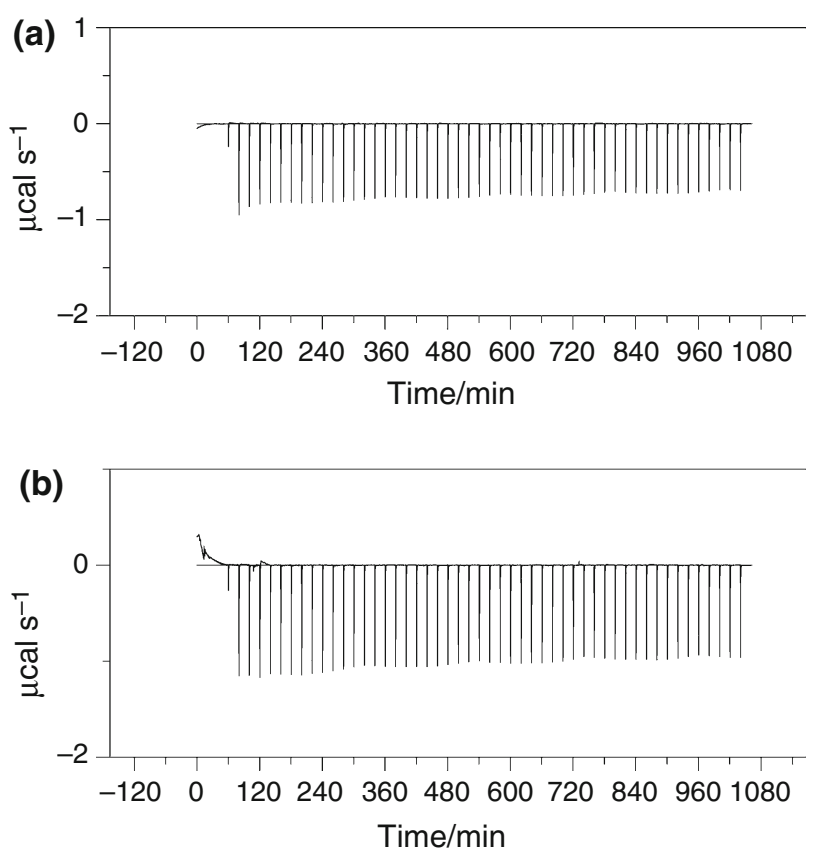

Fig. 8 Curves of thermal power as a function of time for: a titration of $0.5 \mathrm{mM}$ cucurbituril Q7 solution with $5 \mathrm{mM}$ gemcitabine in sodium hydroxide environment $(\mathrm{pH}=12.3)$ and $\mathbf{b}$ dilution of $5 \mathrm{mM}$ gemcitabine in sodium hydroxide environment $(\mathrm{pH}=12.3)$

(Fig. 9b) indicate that cucurbituril Q7 macromolecules do not bind non-protonated gemcitabine molecules in this environment.

To examine the stoichiometry and thermodynamics of the cucurbituril-gemcitabine complex formation in acidic buffer environment with a high drug content, the calorimetric titration was carried out under isothermal conditions $\left(t=25^{\circ} \mathrm{C}\right)$ in aqueous $10 \mathrm{mM}$ formic buffer solution $(\mathrm{pH}=3.8) . \mathrm{pH}$ was stable during the titration. The thermal effects of titrating $0.5 \mathrm{mM}$ cucurbituril Q7 solution with
$5 \mathrm{mM}$ gemcitabine hydrochloride solution were measured in $10 \mathrm{mM}$ formic buffer environment (Figs. 10a, 11a). The thermal effects of the direct interaction between cucurbituril and the drug (Fig. 11b) were determined by subtracting the independently measured thermal effects of diluting gemcitabine (Figs. 10b, 11a) and cucurbituril (Figs. 10c, 11a) from the thermal effects accompanying the titration. Using the identical-site model, the thermal effects of the direct interaction between cucurbituril and gemcitabine were described, calculating (Origin MicroCal 7.0) the binding parameters (Table 2, line 1).

The results obtained indicate that in buffered mixtures of cucurbituril and gemcitabine hydrochloride with a high content of the drug, a thermodynamically stable, supramolecular complex is formed $(\Delta G<0)$. The process of cucurbituril saturation by gemcitabine in $10 \mathrm{mM}$ formic buffer solution $(\mathrm{pH}=3.8)$ is exothermic $(\Delta H<0)$ and is accompanied by an increase in the degree of reagent order $(\Delta S<0)$. The value of stoichiometric parameters $n=$ $0.95 \pm 0.05$ shows that the complex with stoichiometry $1: 1$ is formed in the solution tested. Because $\mathrm{pH}$ values in this buffer solution is comparable with the $\mathrm{pH}$ of studied nonbuffered mixtures in water, the lower binding constant $K$ in formic buffer solution reflects the hindering influence of molecules and ions from buffer mixture on the binding between gemcitabine and cucurbituril Q7.

\section{Reverse isothermal titration calorimetry of gemcitabine hydrochloride titrated with Q7 in formic buffer aqueous solutions}

In order to verify the binding parameters of cucurbiturilgemcitabine complex formation in buffered mixtures with a high content of cucurbituril, the calorimetric titration was carried out under isothermal conditions $\left(t=25^{\circ} \mathrm{C}\right)$ in a 
Fig. 9 a Thermal effects of the forward ITC titration of $0.5 \mathrm{mM}$ cucurbituril Q7 solution with aqueous $5 \mathrm{mM}$ gemcitabine solution (filled black square) in sodium hydroxide environment $(\mathrm{pH}=12.3)$ and corresponding effects of dilution of gemcitabine hydrochloride (filled black circle) in sodium hydroxide environment $(\mathrm{pH}=12.3)$ and $\mathbf{b}$ thermal effects of direct interactions between cucurbituril Q7 and gemcitabine (filled black square) in sodium hydroxide environment $(\mathrm{pH}=12.3)$
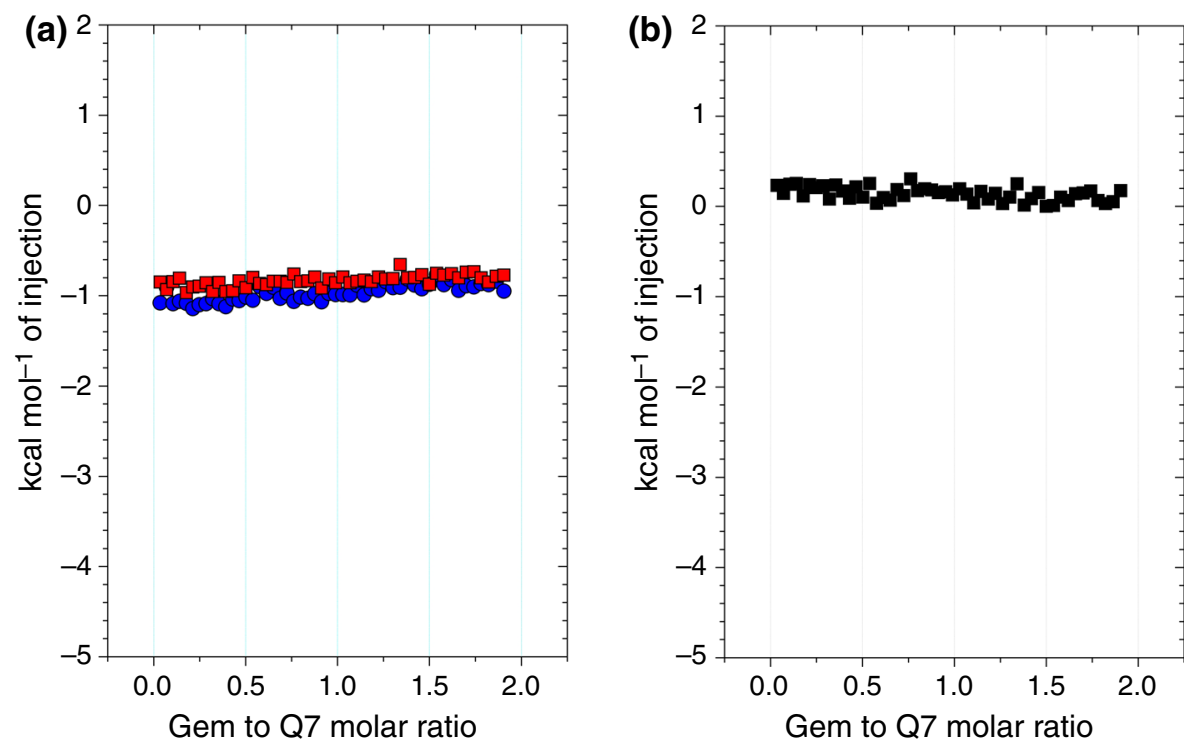
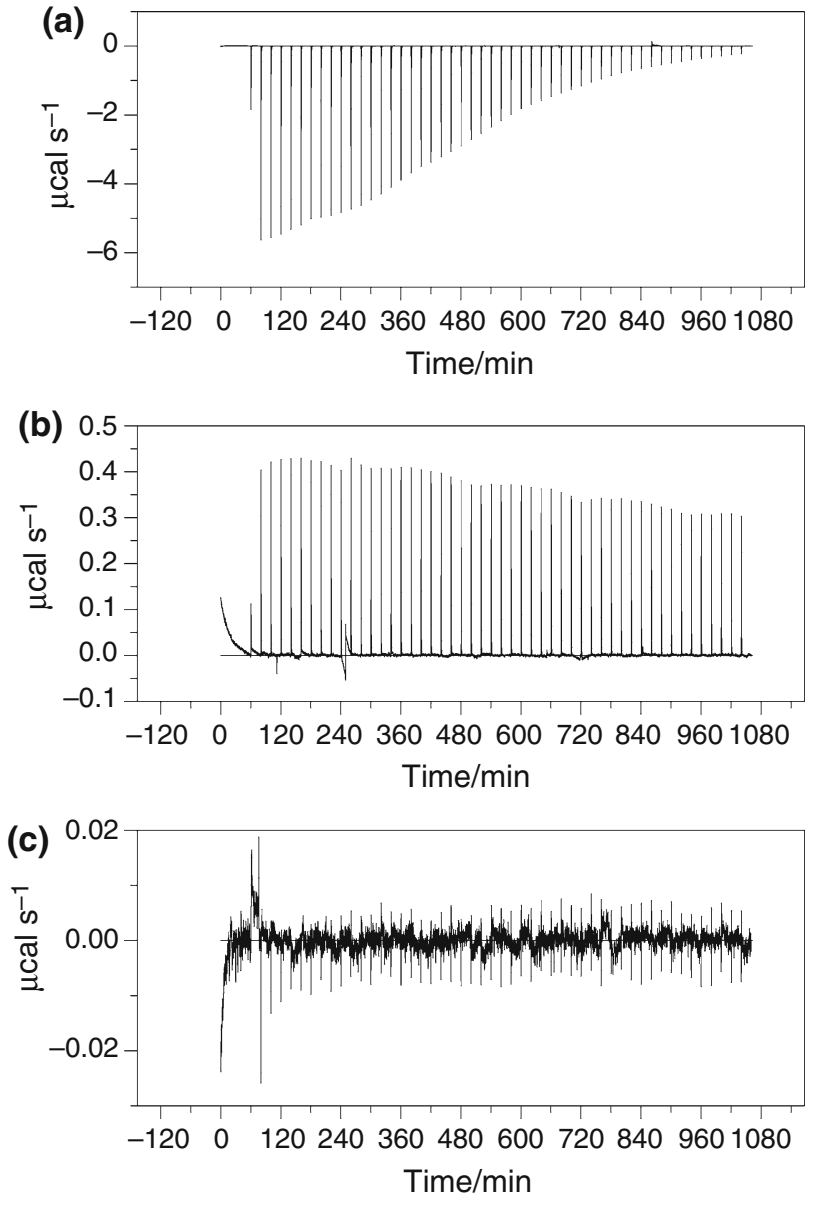

Fig. 10 Curves of thermal power as a function of time for: a titration of $0.5 \mathrm{mM}$ cucurbituril Q7 solution with $5 \mathrm{mM}$ gemcitabine hydrochloride solution in $10 \mathrm{mM}$ formic buffer solution $(\mathrm{pH}=3.8)$, b dilution of $5 \mathrm{mM}$ gemcitabine hydrochloride in $10 \mathrm{mM}$ formic buffer solution ( $\mathrm{pH}=3.8$ ), and $\mathbf{c}$ dilution of $0.5 \mathrm{mM}$ cucurbituril Q7 solution in $10 \mathrm{mM}$ formic buffer solution $(\mathrm{pH}=3.8)$ reverse system in $10 \mathrm{mM}$ formic buffer solution $(\mathrm{pH}=$ 3.8). The thermal effects of titrating the aqueous $120 \mu \mathrm{M}$ solution of gemcitabine hydrochloride with the aqueous $2 \mathrm{mM}$ solution of cucurbituril Q7 were measured (Figs. 12a, 13a). The thermal effects of the direct interaction between the drug and cucurbituril (Fig. 13b) were determined by subtracting from the thermal effects accompanying titration (Figs. 12a, 13a) the independently measured thermal effects of diluting cucurbituril Q7 (Figs. 12b, 13a). The effects of diluting the $120 \mu \mathrm{M}$ solution of gemcitabine hydrochloride (in a cell) with buffer (in a syringe) were negligibly low. Using the identical-site model, the thermal effects of the direct interaction between gemcitabine hydrochloride and cucurbituril were described (Origin MicroCal 7.0) and binding parameters were calculated (Table 2, line 2).

Calculated according to the identical-site model, the parameters of bonding gemcitabine with cucurbituril in $10 \mathrm{mM}$ formic buffer solution $(\mathrm{pH}=3.8$ ) (Table 2, line 2) are similar within the limits of measurement uncertainties to the results of the straightforward titration of cucurbituril with gemcitabine (Table 2, line 1) in the same solvent. The stoichiometric parameter value obtained $n=1.02 \pm 0.07$ confirms that in the $10 \mathrm{mM}$ formic buffer environment ( $\mathrm{pH}=3.8$ ) with the mixture of both components $(\mathrm{Q} 7$ and gemcitabine) with a high content of cucurbituril, a complex with stoichiometry $1: 1$ is formed similar to the results obtained in buffer mixtures of both components with a high content of gemcitabine.

\section{Mass spectrometry of Q7-gemcitabine solution}

Spectrum ESI-MS was recorded in a positive mode for the mixture of gemcitabine hydrochloride and cucurbituril Q7 


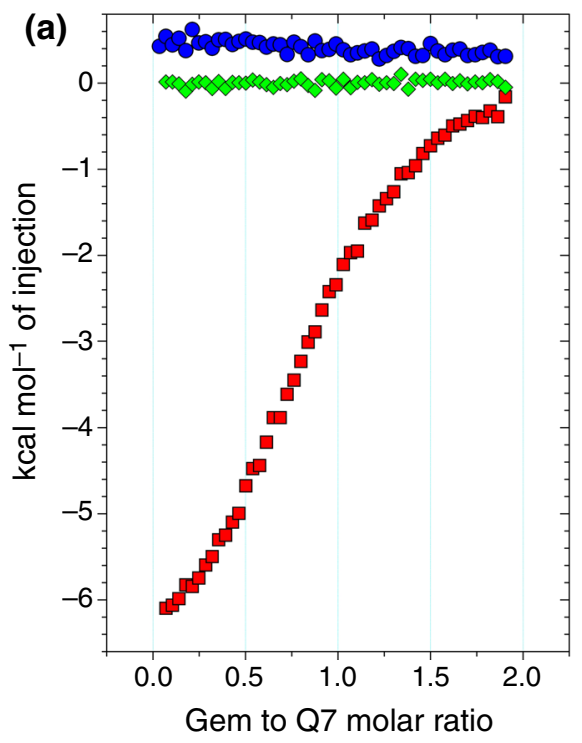

Fig. 11 a Thermal effects of the forward ITC titration of $0.5 \mathrm{mM}$ cucurbituril Q7 solution with $5 \mathrm{mM}$ gemcitabine hydrochloride solution in $10 \mathrm{mM}$ formic buffer solution $(\mathrm{pH}=3.8$ ) (filled black square) and corresponding effects of dilution of gemcitabine hydrochloride (filled black circle) and cucurbituril Q7 (filled black

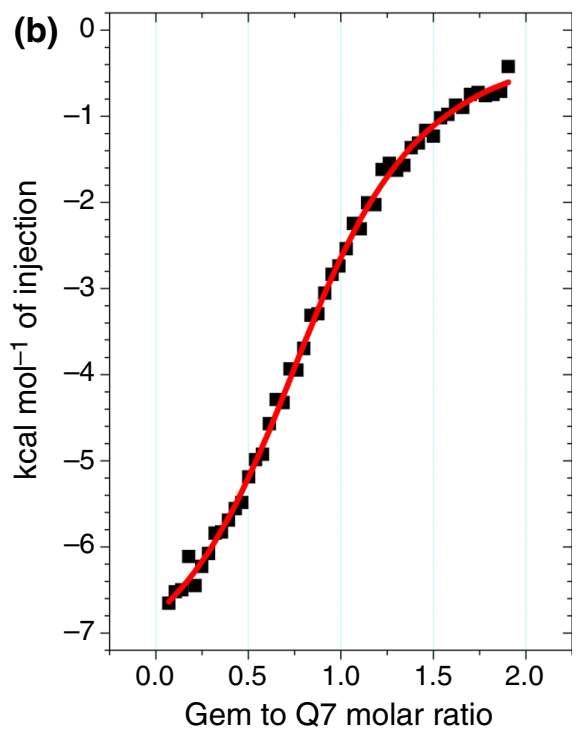

diamond) in $10 \mathrm{mM}$ formic buffer solution $(\mathrm{pH}=3.8)$ and $\mathbf{b}$ thermal effects of direct interactions between cucurbituril Q7 and gemcitabine hydrochloride (filled black square) in $10 \mathrm{mM}$ formic buffer solution $(\mathrm{pH}=3.8)$ described by the identical-site model (solid line)

Table 2 Thermodynamic parameters of the supramolecular cucurbituril-gemcitabine complex formation in $10 \mathrm{mM}$ formic buffer solution $(\mathrm{pH}=3.8)$ environment at $25{ }^{\circ} \mathrm{C}$ determined by the ITC technique

\begin{tabular}{llllll}
\hline Titration type & $n$ & $K / \mathrm{M}^{-1}$ & $\Delta H / \mathrm{kcal} \mathrm{mol}^{-1}$ & $T \Delta S / \mathrm{kcal} \mathrm{mol}^{-1}$ & $\Delta G / \mathrm{kcal} \mathrm{mol}^{-1}$ \\
\hline Q7 with Gem & $0.95 \pm 0.05$ & $13900 \pm 600$ & $-7.8 \pm 0.3$ & $-2.1 \pm 0.4$ & $-5.7 \pm 0.1$ \\
Gem with Q7 & $1.02 \pm 0.07$ & $15000 \pm 2000$ & $-6.9 \pm 0.7$ & $-1.2 \pm 0.9$ & $-5.7 \pm 0.2$ \\
\hline
\end{tabular}

in an aqueous solution of sodium acetate (Fig. 14). The molar ratio of gemcitabine to cucurbituril Q7 in the mixture tested amounted to 2/1. Particular peaks in spectrum ESI-MS can be interpreted as follows: $m / z 725.0$ as $[\mathrm{Q} 7+\mathrm{Gem}+\mathrm{H}+\mathrm{Na}]^{2+}, \quad m / z \quad 845.6 \quad$ as $[\mathrm{Q} 7+2 \mathrm{Gem}+2 \mathrm{H}]^{2+}, m / z 1427.0$ as $[\mathrm{Q} 7+\mathrm{Gem}+\mathrm{H}]^{+}$, and $m / z, 1448.8$ as $[\mathrm{Q} 7+\mathrm{Gem}+\mathrm{Na}]^{+}$. The molecular peaks recorded explicitly indicate the formation of not only the supramolecular complex with stoichiometry $1: 1$, but also another complex with stoichiometry $2: 1\left(\mathrm{~L}_{2} \mathrm{Q}\right)$, in which the macromolecule of cucurbituril bonds two cations of gemcitabine. The formation of complex with stoichiometry $2: 1\left(\mathrm{~L}_{2} \mathrm{Q}\right)$ requires an excess of ligand $\mathrm{L}$ in the mixture and is observed in the gaseous phase. A peak that would correspond to a complex with stoichiometry 1:2 $\left(\mathrm{LQ}_{2}\right)$ and a double charge was not observed. A hypothetical peak corresponding to a complex with stoichiometry 1:2 (LQ $\left.\mathrm{L}_{2}\right)$ and a single charge would be beyond the measurement range $m / z$ 699.5-1600.5.

\section{Discussion}

The results of isothermal calorimetric titrations in the straightforward system (excess drug after ending the experiment) and reverse system (excess macrocycle after ending the experiment) unanimously indicate that a thermodynamically stable supramolecular complex with stoichiometry $1: 1$ is formed in water (Table 1). The thermodynamic function values of complex formation, calculated from both types of titration, indicate that the process of bonding gemcitabine hydrochloride by cucurbituril Q7 is exothermic $(\Delta H<0)$. This indicates a predominance of the energetic effects of the direct interactions between functional groups of gemcitabine and cucurbituril molecules over the effects of their partial dehydration preceding the complex formation. The bonding of gemcitabine by cucurbituril Q7 in water is, however, accompanied by an increase in the degree of reagent order $(\Delta S<0)$, which indicates that the driving force of the process is in this case a favorable (exothermic) value of the enthalpy of complex formation in an aqueous medium. Exothermic 

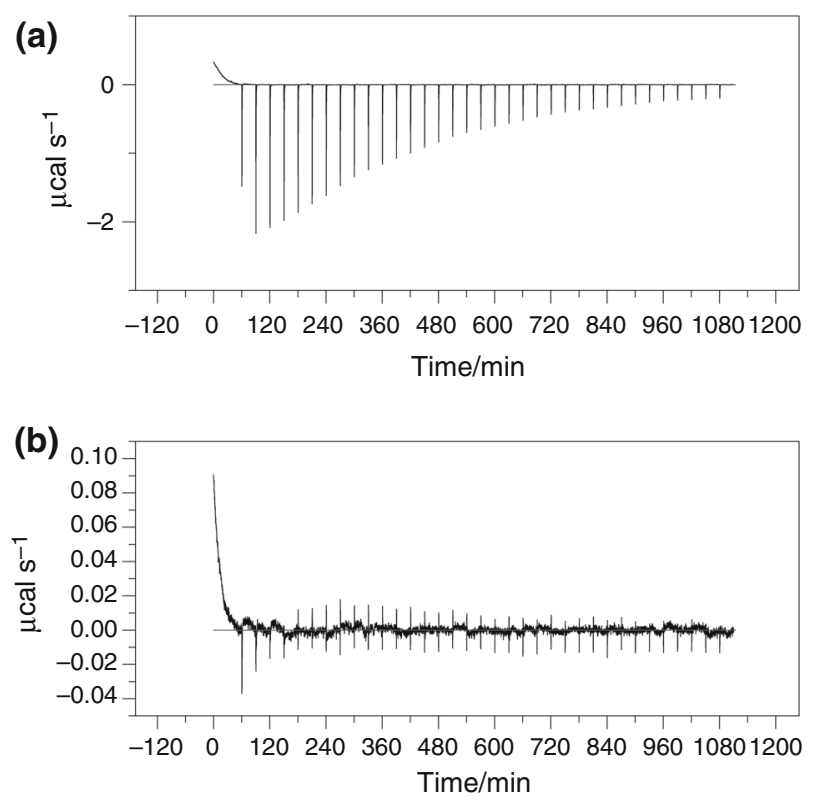

Fig. 12 Curves of thermal power as a function of time for: a titration of $120 \mu \mathrm{M}$ gemcitabine hydrochloride solution with $2 \mathrm{mM}$ cucurbituril Q7 solution in $10 \mathrm{mM}$ formic buffer solution $(\mathrm{pH}=3.8)$ and b dilution of $2 \mathrm{mM}$ cucurbituril Q7 solution in $10 \mathrm{mM}$ formic buffer solution $(\mathrm{pH}=3.8)$

effects of the direct interactions between cucurbituril Q7 and gemcitabine hydrochloride indicate that during titration, weaker electrostatic interactions and hydrogen bonds of the system component molecules with water molecules are replaced by comprehensively stronger electrostatic interactions, hydrogen bonds, and hydrophobic interactions between the functional groups of the ligand (drug) and the macrocycle tested.

Gemcitabine hydrochloride dissolved in aqueous solutions shows acidic character $\left(p K_{\mathrm{a}}=3.95\right)$ due to protonating the nitrogen atom of the pyridimine part in the drug molecule [32]. Once the titration procedure is completed, the mixture tested shows acidity, $\mathrm{pH} 3.8$, caused by the presence of trace quantities of acidic impurities in the cucurbituril tested (the macrocycles are synthesized in a medium of strong mineral acid) and the acidic hydrolysis of gemcitabine hydrochloride (cationic Brønsted acid). The deprotonation constant of gemcitabine cation, $\mathrm{pH}$-metrically determined in aqueous solutions, $p K_{\mathrm{a}}=3.95$ allows to determine distribution curves of the non-protonated (L$\mathrm{NH}_{2}$ ) and protonated $\left(\mathrm{L}-\mathrm{NH}_{3}^{+}\right)$form of gemcitabine. According this distribution, at $\mathrm{pH}=3.8$, about $60 \%$ of gemcitabine molecules occur in a cationic form. This confirms the capability of cucurbiturils to bond cationic low-molecular ligands, reported also in literature [33]. The cationic center of the protonated gemcitabine molecules seems to react during the complex formation with the negatively charged fragments of cucurbituril Q7.

The results of isothermal calorimetric titrations in the straightforward system (excess drug after ending the experiment) in sodium hydroxide environment $(\mathrm{pH}=12.3$ ) show that from both presented in the gemcitabine solutions' species (cationic and neutral), only cations of the drug show high affinity toward macromolecule Q7, so for this drug, a difference in a positive or neutral charge is enough to hinder binding phenomenon. If so, the stoichiometry may still be around 1:1, but could also be lowered depending on which species predominates in a given environment.

Results of ITC titration of bonding gemcitabine with cucurbituril in $10 \mathrm{mM}$ formic buffer solution $(\mathrm{pH}=3.8)$ (Table 2) show similar directions of changes of the thermodynamic functions $(\Delta H<0$ and $\Delta S<0$ ), but the binding constant $K$ of supramolecular complex formation is lower
Fig. 13 Thermal effects of the reverse ITC titration of $120 \mu \mathrm{M}$ gemcitabine hydrochloride solution with $2 \mathrm{mM}$ cucurbituril Q7 solution (filled black square) in $10 \mathrm{mM}$ formic buffer solution $(\mathrm{pH}=3.8)$ and corresponding effects of dilution of cucurbituril Q7 (filled black circle) in $10 \mathrm{mM}$ formic buffer solution $(\mathrm{pH}=3.8)$ and $\mathbf{b}$ thermal effects of direct interactions between gemcitabine hydrochloride and cucurbituril Q7 (filled black square) in $10 \mathrm{mM}$ formic buffer solution $(\mathrm{pH}=3.8)$ described by the identical-site model (solid line)
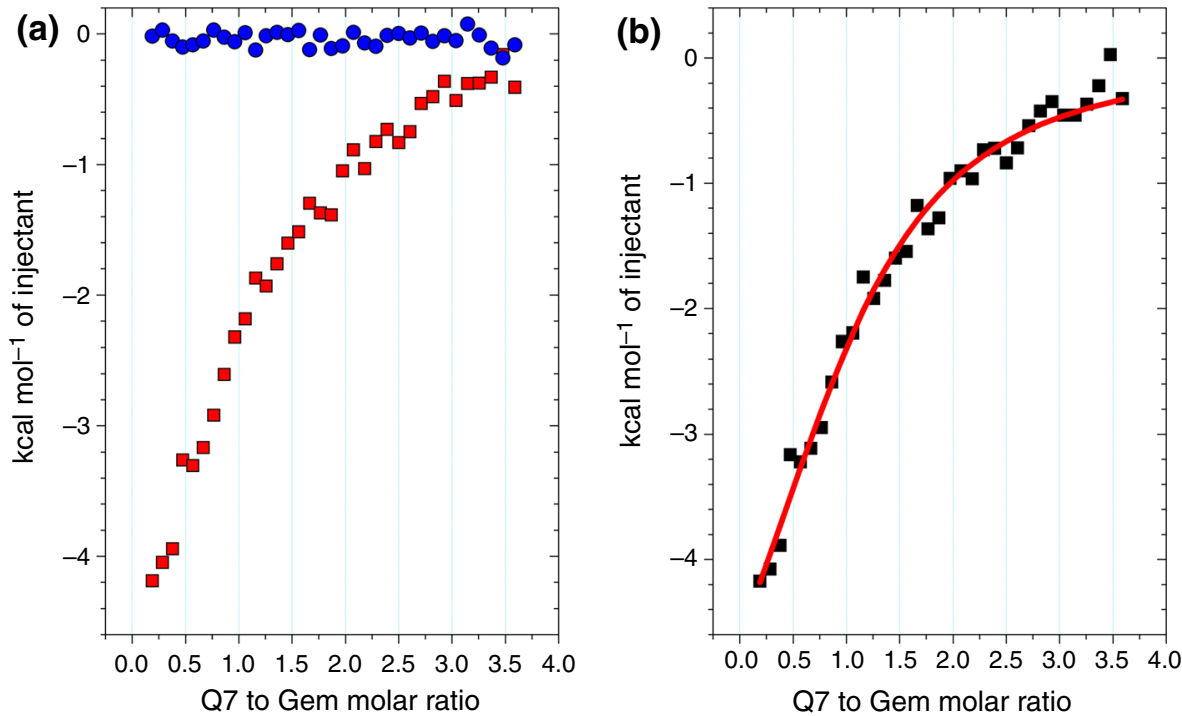


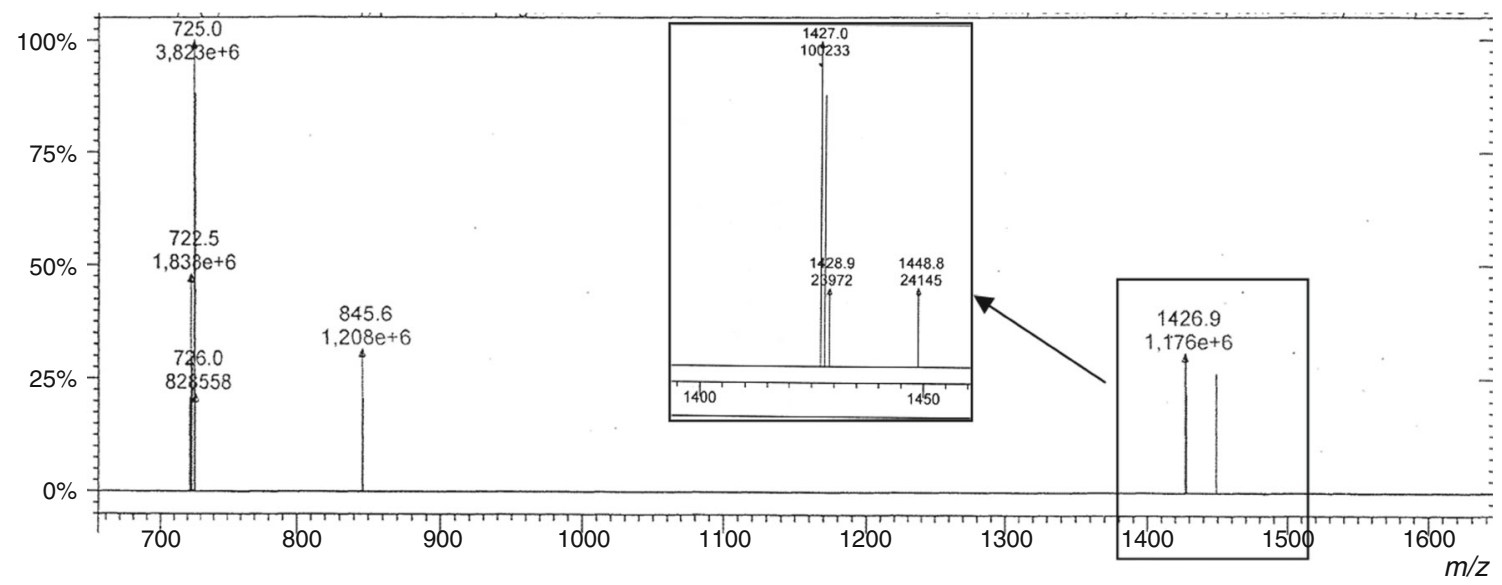

Fig. 14 Ion ESI mass spectrum of the gemcitabine hydrochloride and cucurbituril Q7 mixture in aqueous sodium acetate solution. Molar ratio of gemcitabine to cucurbituril was $2 / 1$

in buffer environment in comparison with aqueous (nonbuffered) solution of both components. This reflects the hindering influence of molecules (non-dissociated formic acid) and ions (formic anions and sodium cations) from buffer mixture on the binding between gemcitabine and cucurbituril Q7. Counterions and other molecules which constitute the (more complex) buffer environment may shelter the active sites of gemcitabine cation and cucurbituril macromolecule and inhibit the direct interactions between nano-carrier and its ligand.

The observed molecular peaks in the spectrum of the mixtures of gemcitabine hydrochloride, cucurbituril Q7, and sodium acetate indicate that the presence of ions derived from electrolyte dissociation, molar excess of gemcitabine in relation to the macrocycle, and the gaseous phase with dissipated component of the system tested influence the stoichiometry of the complexes formed. The mixtures with a high gemcitabine content tested by the ESI-MS technique contain not only the supramolecular complex with stoichiometry $1: 1$ but also that with stoichiometry $2: 1\left(\mathrm{~L}_{2} \mathrm{Q}\right)$.

The examination of the interaction thermodynamics of the supramolecular system components in pure water allows one to indicate these nano-carrier-ligand pairs that should be selected for further biochemical and biomedical studies. However, in practice, we cannot administer a therapeutic complex suspended in pure water to patients by injection. Such a mixture is strongly hypotonic and would cause a shock in the organism treated [34, 35].

Thus, to safely administer the drug bonded with cucurbituril nano-carrier by injection, it is a necessary condition to stabilize its $\mathrm{pH}$ and provide the iso-osmosity of the solvent used with the patient body fluids, especially his/her blood. Therefore, to administer the supramolecular complex containing the transported drug (gemcitabine cation) to a patient, it is indispensable to suspend the complex in an aqueous medium rich in counterions with properties that would buffer and stabilize the ionic power and osmotic pressure of the medium used. Cucurbituril Q7 shows, however, strong complex-forming properties in relation to the mixture of zwitterions of many Good's buffers (e.g., HEPES, PIPES), used in biochemistry as media with a high stability and biochemical inertia capability [36]. The direct synthesis of cucurbituril-drug complex in a buffer medium is made difficult on account of "overcoating" the functional groups of the carrier and drug with the counterions of buffer medium.

Thus, to load the nano-carrier with a useful ligand, it is worth using an aqueous medium (poor in counterions) as indirect solvent, stabilizing the stoichiometry and facilitating the interaction between the functional groups of cucurbituril and drug molecules. Therefore, it is better to load the carrier (cucurbituril) with the drug in water and then to impart iso-osmosity and desirable $\mathrm{pH}$ value to the obtained solution containing the therapeutic complex. Such a two-stage procedure should allow one to efficiently and reproducibly obtain the suspended in buffers' supramolecular complexes with a defined stoichiometry that could be then gently and without harm to the patient organism administrated by injection.

The calorimetrically determined, a relatively high value of the equilibrium constant of complex formation in a pure water $(\log K>4.9)$ shows that the macrocycle of cucurbituril Q7 can be used in the future as non-toxic nanotransporter of the highly toxic drug-gemcitabine hydrochloride in biomedical applications, reducing the side effects of the treatment and improving its comfort. In the future, we are going to use the calorimetric titration technique to study the thermodynamic of the cucurbiturilgemcitabine complexes (1) in an aqueous medium of hydrochloric acid, as well as (2) in formic buffer at different $\mathrm{pH}$ values and electrolyte concentrations, which 
should enable to study the influence of more complex environment to the interactions between cationic species and cucurbituril Q7. We also plan to use the technique of mass spectrometry to examine the stoichiometry of complexes in the mixtures containing an excess of gemcitabine or cucurbituril.

\section{Conclusions}

The presented results of calorimetric titration under isothermal conditions $\left(25^{\circ} \mathrm{C}\right)$ show that cucurbituril Q7 molecule bonds the cationic antitumor drug-gemcitabine hydrochloride $(\mathrm{Gem})$, forming both in pure water and in formic buffer (10 mM, pH 3.8), a thermodynamically stable supramolecular complex with stoichiometry 1:1 (LQ). MS results confirm the formation of complex 1:1 and additionally show that in mixtures with a high content of gemcitabine, complexes with higher stoichiometry can also be formed.

Acknowledgements The study was financed from the Grant for Development of Young Researchers from the Faculty of Chemistry, University of Lodz, 2017.

Open Access This article is distributed under the terms of the Creative Commons Attribution 4.0 International License (http://creative commons.org/licenses/by/4.0/), which permits unrestricted use, distribution, and reproduction in any medium, provided you give appropriate credit to the original author(s) and the source, provide a link to the Creative Commons license, and indicate if changes were made.

\section{References}

1. Grząbka-Zasadzińska A, Klapiszewski Ł, Bula K, Jesionowski T, Borysiak S. Supermolecular structure and nucleation ability of polylactide-based composites with silica/lignin hybrid fillers. J Therm Anal Calorim. 2016;126:263-75.

2. El-Boraey HA, Serag El-Din AA, Sayed IE. New complexes with 19-membered pyridine-based macrocycle ligand. J Therm Anal Calorim. 2017;129:1243-53.

3. Katoch S, Bajju GD, Devi G, Ahmed A. Synthesis, thermoanalytical and spectroscopic characterization of newly synthesized macrocyclic complexes of thallium(III) and tin(IV). J Therm Anal Calorim. 2017;130:2157-65.

4. Lörinczy D. Thermal analysis in biological and medical applications. J Therm Anal Calorim. 2017;130:1263-80.

5. Wszelaka-Rylik M. Thermodynamics of b-cyclodextrin-ephedrine inclusion complex formation and covering of nanometric calcite with these substances. J Therm Anal Calorim. 2017; 127:1825-34

6. Bertolino V, Cavallaro G, Lazzara G, Milioto S, Parisi F. Crystallinity of block copolymer controlled by cyclodextrin. J Therm Anal Calorim. 2018. https://doi.org/10.1007/s10973-018-6982-8.

7. Shchepotina EG, Pashkina EA, Yakushenko EV, Kozlov VA. Cucurbiturils as containers for medicinal compounds. Nanotechnol Russ. 2011;6:773-9.
8. Wang L, Li L-L, Fan Y-S, Wang H. Host-guest supramolecular nanosystems for cancer diagnostics and therapeutics. Adv Mater. 2013;25:3888-98.

9. Premkumar T, Lee Y, Geckeler KE. Macrocycles as a tool: a facile and one-pot synthesis of silver nanoparticles using cucurbituril designed for cancer therapeutics. Chem Eur J. 2010;16:11563-6.

10. Pennakalathil J, Jahja E, Özdemir ES, Konu Ö, Tuncel D. Red emitting, cucurbituril-capped, pH-responsive conjugated oligomer-based nanoparticles for drug delivery and cellular imaging. Biomacromolecules. 2014;15:3366-74.

11. Park KM, Suh K, Jung H, Lee D-W, Ahn Y, Kim J, et al. Cucurbituril-based nanoparticles: a new efficient vehicle for targeted intracellular delivery of hydrophobic drugs. Chem Commun. 2009;1:71-3. https://doi.org/10.1039/B815009E.

12. Lagona J, Mukhopadhyay P, Chakrabarti S, Isaac L. The cucurbit[n]uril family. Angew Chem Int Ed. 2005;44:4844-70.

13. Day A, Arnold AP, Blanch RJ, Snushall B. Controlling factors in the synthesis of cucurbituril and its homologues. J Org Chem. 2001;66:8094-100.

14. Lee JW, Samal S, Selvapalam N, Kim H-J, Kim K. Cucurbituril homologues and derivatives: new opportunities in supramolecular chemistry. Acc Chem Res. 2003;36:621-30.

15. Barrow SJ, Kasera S, Rowland MJ, Barrio JD, Scherman OA. Cucurbituril-based molecular recognition. Chem Rev. 2015; 115:12320-406.

16. Logvinenko V, Mitkina T, Drebushchak V, Fedin V. Thermal transformations of the supramolecular compound of cucurbit[8]uril with cobalt(III) complex $\left.\{\text { trans-[Co(en })_{2} \mathrm{Cl}_{2}\right] @$ $\mathrm{CB}[8]\} \mathrm{Cl} \cdot 17 \mathrm{H}_{2} \mathrm{O}$. J Therm Anal Calorim. 2011;105:103-6.

17. Huang Y, Xue S-F, Zhu Q-J, Zhu T. Inclusion interactions of cucurbit[7]uril with adenine and its derivatives. Supramol Chem. 2008;20:279-87.

18. Montes-Navajas P, Gonzalez-Bejar M, Scaiano JC, Garcia H. Cucurbituril complexes cross the cell membrane. Photochem Photobiol Sci. 2009;8:1743-7.

19. Palecz B, Buczkowski A, Piekarski H, Kılınçarslan Ö. Thermodynamic interaction between PAMAM G4- $\mathrm{NH}_{2}, \mathrm{G} 4-\mathrm{OH}, \mathrm{G} 3.5-$ $\mathrm{COONa}$ dendrimers and gemcitabine in water solutions. Int $\mathrm{J}$ Second Metab. 2016;3:21-6.

20. Pili B, Bourgaux C, Meneau F, Couvreur P, Ollivon M. Interaction of an anticancer drug, gemcitabine, with phospholipid bilayers. J Therm Anal Calorim. 2009;98:19-28.

21. Catalog of products of Sigma-Aldrich. http://www.sigmaaldrich. com.

22. Catalog of products of Selleckchem. http://www.selleckchem. com.

23. Catalog of products of MedKoo Biosciences. http://www.med koo.com.

24. Catalog of products of SantaCruz Biotechnology. https://www. scbt.com.

25. Experimental value of $\mathrm{pKa}$ from the Database DrugBank. https:// www.drugbank.ca.

26. Ghosh I, Nau WM. The strategic use of supramolecular pKa shifts to enhance the bioavailability of drugs. Adv Drug Deliv Rev. 2012;64:764-83.

27. Khorwal V, Nudurupati U, Mondal SI, Datta A. Interplay of hydrophobic and electrostatic interactions in modulation of protonation-deprotonation equilibria of two positional isomers in their complexes with cucurbiturils. J Phys Chem C. 2017; 121:5379-88.

28. Gans P, Sabatini A, Vacca A. Investigation of equilibria in solutions. Determination of equilibrium constants with the HYPERQUAD suite of programs. Talanta. 1996;43:1739-53.

29. Alderighi L, Gans P, Ienco A, Peters D, Sabatini A, Vacca A. Hyperquad simulation and speciation (HySS): a utility program 
for the investigation of equilibria involving soluble and partially soluble species. Coord Chem Rev. 1999;184:311-8.

30. ITC Date Analysis in Origin-Tutorial Guide. Northampton: MicroCal; 2004.

31. VP-ITC MicroCalorimeter User's manual. Northampton: MicroCal; 2004.

32. Liu D-H, Zhao W-W, Li Z-X. To determine the half-life for gemcitabine hydrochloride using microcalorimetry. J Therm Anal Calorim. 2014;115:1793-7.
33. Assaf KI, Nau WM. Cucurbiturils: from synthesis to high-affinity binding and catalysis. Chem Soc Rev. 2015;44:394-418.

34. Sowemimo-Coker SO. Red blood cell hemolysis during processing. Transfus Med Rev. 2002;16:46-60.

35. Hoffman JF. Physiological characteristics of human red blood cell ghosts. J Gen Physiol. 1958;42:9-28.

36. Selinger AJ, Macartney DH. Cucurbit[7]uril complexations of Good's buffers. RSC Adv. 2017;7:42513-8. 